\title{
Pengaruh gelling agent kombinasi karbopol dan hpmc terhadap sifat fisik sediaan gel ekstrak etanol daun bandotan (ageratum conyzoides I) The effect of gelling agent combination of carbopol and hpmc on the physical properties of the preparation of bandotan (ageratum conyzoides I) leaf ethanol extract gel
}

\author{
Intan Siswi Saputri ${ }^{1}$, Dwi Bagus Pambudi ${ }^{2 *}$, Wirasti $^{3}$, St Rahmatullah ${ }^{4}$ \\ 1,2,3,4, Program Studi Sarjana Farmasi, Fakultas Ilmu Kesehatan, Universitas Muhammadiyah \\ Pekajangan Pekalongan, Indonesia \\ *email : dwibagus589@umpp.ac.id
}

\begin{abstract}
Gelling agent is a base in gel preparations that are used to thicken and make drug preparations or cosmetic preparations stable. Natural ingredients have been widely used because they are efficacious as medicine. One of them is bandotan plant (Ageratum Conyzoides $L$ ). This study aims to determine the effect of the combination of gelling agent carbopol and HPMC on the physical properties of the gel preparation of bandotan leaf ethanol extract. In this study 3 formulations of gel preparations of bandotan leaf ethanol extract were made with different concentrations of carbopol and HMPC. This research is an experimental research and uses qualitative and quantitative data collection methods from laboratory research. The extraction method used in this study is the maceration method with $96 \%$ ethanol as solvent. The prepared gel preparations were tested including organoleptic tests, $\mathrm{pH}$ tests, adhesion tests and dispersion tests. The results of this study indicate that there is an effect on the gelling agent of the combination of carbopol and HPMC on the gel preparation of the ethanol extract of bandotan leaves (Ageratum conyzoides L) in formula III with a ratio of gelling agent carbopol and HPMC 0.5\%: $6 \%$ which is the best gel seen. from $\mathrm{pH}$ test, dispersion test and adhesion test.
\end{abstract}

Keywords: Ageratum Conyzoides L; gel; karbopol; hpmc; gelling agent

\begin{abstract}
Abstrak
Gelling agent merupakan basis dalam sediaan gel yang digunakan untuk mengentalkan dan menjadikan sediaan obat atau sediaan kosmetik tetap stabil. Bahan alam sudah banyak digunakan karenaberkhasiat sebagai obat. Salah satunya adalah tumbuhan bandotan (Ageratum Conyzoides L). Penelitian ini bertujuan untuk mengetahui adanya pengaruh kombinasi gelling agent karbopol dan HPMC terhadap sifat fisik sediaan gel ekstrak etanol daun bandotan. Dalam penelitian ini dibuat 3 formulasi sediaan gel ekstrak etanol daun bandotan dengan perbedaan konsentrasi karbopol dan HMPC. Penelitian ini merupakan penelitian experimental dan menggunakan metode pengumpulan data kualitatif dan kuantitatif dari penelitian laboratorium. Metode ekstraksi yang digunakan dalam penelitian ini adalah metode maserasi dengan pelarut etanol $96 \%$. Sediaan gel yang telah jadi dilakukan pengujian diantaranya uji organoleptis, uji pH , uji daya lekat danuji daya sebar. Hasil dari penelitian ini menunjukkan bahwa terdapat pengaruh padagelling agentkombinasi karbopol dan HPMC terhadap sediaan gel ekstrak etanol daun bandotan (Ageratum conyzoides $L$ ) pada formula III dengan perbandingan gelling agent karbopol dan HPMC 0,5\% : 6\% yang merupakan gel paling baik dilihat dari uji pH , uji daya sebar dan daya lekat.
\end{abstract}

Kata Kunci : Ageratum Conyzoides L; gel; karbopol; hpmc; gelling agent 


\section{Prosiding Seminar Nasional Kesehatan Lembaga Penelitian dan Pengabdian Masyarakat Universitas Muhammadiyah Pekajangan Pekalongan

\section{Pendahuluan}

Di masa pandemi seperti ini, semakin susah mencari produk dan bahan-bahan makanan dan juga obat, baik diwarung maupun diapotek sekalipun. Sehingga semakin banyak masyarakat yang memanfaatkan bahan-bahan alam atau back to nature. Salah satu tumbuhan yang berasal dari alam dan berkhasiat sebagai obat, terutama obat luka yaitu daun bandotan (Ageratum Conyzoides L). Masyarakat pedesaan khususnya pegunungan banyak yang menggunakan daun ini sebagai obat luka berdarah, pengaplikasiannya ditumbuk pakai batu dan langsung dioleskan pada tangan atau bagian tubuh yang sakit [5].

Berdasarkan penelitian dari melsi mengkido, dkk 2019 menunjukkan bahwa daun bandotan (Ageratum conyzoides L.) mengandung senyawa aktif berupa terpenoid, fenol, saponin dan alkaloid yang mampu untuk menghambat pertumbuhan bakteri patogen [5].

Oleh karena itu, penulis mengembangkan obat untuk memenuhi kebutuhan masyarakat yang bertujuan untuk memberikan efek terapi obat. Sediaan farmasi telah banyak dilakukan pengembangan seperti sediaan semisolid yang digunakan untuk topical yang memiliki kelebihan praktis, mudah dibawa dan mudah dipakai. Sediaan farmasi yang dapat diaplikasikan untuk kulit salah satunya adalah gel [9].

Faktor penting dalam formulasi gel salah satunya yaitu gelling agent. Masingmasing gelling agent memiliki karakteristik. Penelitian ini bertujuan untuk mengetahui adanya pengaruh kombinasi gelling agent karbopol dan HPMC terhadap sifat fisik sediaan gel ekstrak etanol daun bandotan. Menurut Tambunan dan Sulaiman, 2018 Karbopol merupakan basis gel yang kuat dan aman digunakan secara topikal karena tidak menimbulkan hipersensitivitas pada kulit manusia serta melekat dengan baik. Sedangkan Menurut penelitian Titis Rahayu,dkk 2016. Karbopol merupakan faktor yang paling dominan meningkatkan viskositas dan daya lekat. HPMC merupakan basis gel yang dapat menghasilkan gel yang netral, jernih stabil pada pH 3 sampai 11 dan stabil dalam penyimpanan jangka lama serta memiliki resistensi yang baik terhadap serangan mikroba. Apabila karbopol dan HPMC digunakan basis tunggal dibandingkan dengan penggunaan basis kombinasi keduanya, maka lebih baik penggunaan basis kombinasi keduanya karena dapat membentuk massa gel yang lebih baik secara fisik [12].

Berdasarkan uraian diatas, maka penulis tertarik untuk meneliti "pengaruh Gelling agent kombinasi karbopol dan HPMC Terhadap sifat fisik sediaan gel ekstrak etanol daun bandotan (Ageratum Conyzoides L).

\section{Metodologi Penelitian}

Bahan

Bahan yang digunakan meliputi daun bandotan yang berasal dari Desa Sidomulyo, Kecamatan Lebakbarang, etanol 96\%, HPMC, Karbopol, Triethanolamin, Metil paraben, dan Aquades. 


\section{Prosiding Seminar Nasional Kesehatan \\ Lembaga Penelitian dan Pengabdian Masyarakat \\ Universitas Muhammadiyah Pekajangan Pekalongan}

Alat

Alat yang digunakan meliputi timbangan analitik (OHAUS), batang pengaduk, spatula, alumunium foil, gelas beaker (PYREX), tabung reaksi (PYREX), ayakan no.40, oven, rotary evaporator (HEIDOLPH), alat uji daya sebar, alat uji daya lekat.

\section{PROSEDUR PENELITIAN}

1. Determinasi tumbuhan bandotan

Determinasi dilakukan di Laboratorium Biologi, Fakultas Sains dan Teknologi Terapan Universitas Ahmad Dahlan, Yogyakarta.

2. Pembuatan ekstrak etanol daun bandotan

Ekstraksi sampel daun bandotan (Ageratum conyzoides L) menggunakan metode maserasi. Serbuk kering daun bandotan ditimbang sebanyak 1000 gram dimasukkan kedalam wadah kaca lalu ditambahkan dengan 5 liter pelarut etanol 96\% direndam selama 5 hari dengan sesekali diaduk selama 1 jam setiap 24jam sekali. Hasil ekstraksi disaring menggunakan corong, kemudian dilakukan remaserasi dengan 3 liter etanol 96\% dan dilakukan pengadukan kembali setiap 24 jam sekali selama 1 jam. Dilakukan penyaringan kembali, kemudian hasil filtrat maserasi pertama disatukan dengan hasil filtrat remaserasi. Hasil filtrat yang diperoleh dikentalkan menggunakan rotary evaporator pada suhu $60^{\circ} \mathrm{C}$, ekstrak cair yang diperoleh diuapkan menggunakan oven. Setelah dipekatkan kemudian diperoleh ekstrak kental. Kemudian dilakukan perhitungan rendemen pada akhir tahap ekstraksi [6].

3. Penentuan Formula Gelling Agent

Penelitian ini membuat 3 formula dengan konsentrasi Karbopol dan HPMC yang berbeda.

4. Pembuatan Sediaan Gel

Panaskan aquades hingga mendidih. Karbopol didispersikan dalam aquades tesebut menggunakan stirer. Kemudian ditambahkan triethanolamin sehingga terbentuk gel. HPMC didispersikan dengan aquades hingga mengembang. Lalu ditambahkan kedalam karbopol, diaduk hingga homogen. Metil paraben dilarutkan dalam air panas, setelah larut dimasukkan dalam massa gel. Ekstrak daun bandotan dtambahkan dalam massa gel dan diaduk dengan stirer sampai homogen, sambil menambahkan sisa air.

5. Uji Sifat Fisik Sediaan

a. Uji Organoleptik

Uji organoleptik meliputi bentuk, warna, dan bau dari gel yang dilakukan secara visual [12].

b. $\quad \mathrm{Uji} \mathrm{pH}$

Pemeriksaan $\mathrm{pH}$ dilakukan menggunakan stik $\mathrm{pH}$, warna yang muncul dibandingkan dengan standar warna pada kisaran $\mathrm{pH}$ yang sesuai yaitu 4,5-6,5 [12] 


\section{Prosiding Seminar Nasional Kesehatan \\ Lembaga Penelitian dan Pengabdian Masyarakat

c. Uji Daya Lekat

Gel sebanyak 0,1 gram dioleskan di atas kaca objek yang ditandai dengan luas $2 \times 2 \mathrm{~cm}$. Kaca obyek lain diletakkan diatas gel tersebut. Beri beban $1 \mathrm{~kg}$ di atas kaca objek selama 5 menit, kemudian kaca obyek dipasang pada alat uji daya lekat yang telah diberi beban 80 gram. Waktu dicatat setelah kedua obyek tersebut memisah/terlepas [12].

d. Uji Daya Sebar

Gel sebanyak 0,5 gram diletakkan ditengah kaca, ditutup dengan kaca lain yang telah ditimbang dan dibiarkan selama 1 menit, lalu diukur diameter sebar gel. Selanjutnya diberi penambahan beban setiap 1 menit sebesar 50 gram, 100 gram, 150 gram, 200 gram, dan 250 gram. Lalu diukur diameter sebar gel [12].

\section{Hasil dan Pembahasan}

Tabel 1. Formulasi Sediaan Gel Ekstrak Etanol Daun Bandotan

\begin{tabular}{|c|c|c|c|c|}
\hline \multirow{2}{*}{ Bahan } & \multicolumn{3}{|c|}{ Formula } & \multirow{2}{*}{ Fungsi } \\
\cline { 2 - 4 } & F1 & F2 & F3 & \\
\hline $\begin{array}{c}\text { Ekstrak kental } \\
\text { daun bandotan } \\
\begin{array}{c}\text { (Ageratum } \\
\text { Conyzoides } L)\end{array}\end{array}$ & 7,5 & 7,5 & 7,5 & Bahan Aktif \\
\hline Karbopol & 2 & 0,875 & & \\
\hline HPMC & 4 & 5,5 & 6,5 & Gelling Agent \\
\hline TEA & 0,5 & 0,5 & 0,5 & Pelling Agent \\
\hline Metil Paraben & 0,2 & 0,2 & 0,2 & Pengawet \\
\hline Aquadest & ad 100 & ad 100 & ad 100 & Bahan Aktif \\
\hline
\end{tabular}

Tabel 2. Hasil Uji Organoleptis

\begin{tabular}{|c|c|c|c|}
\hline Formula & Bentuk & Warna & Bau \\
\hline F1 & Kental & Hijau Kehitaman & $\begin{array}{c}\text { Khas Ekstrak } \\
\text { Etanolik }\end{array}$ \\
\hline F2 & Kental & Hijau Kehitaman & $\begin{array}{c}\text { Khas Ekstrak } \\
\text { Etanolik }\end{array}$ \\
\hline F3 & Kental & Hijau Kehitaman & $\begin{array}{c}\text { Khas Ekstrak } \\
\text { Etanolik }\end{array}$ \\
\hline
\end{tabular}

Tabel 3. Hasil Uji pH

\begin{tabular}{|c|c|c|c|l|}
\hline \multirow{2}{*}{ Replikasi } & \multicolumn{3}{|c|}{ Hasil Pengamatan } & \multirow{2}{*}{ Pustaka } \\
\cline { 2 - 4 } & F1 & F2 & F3 & \\
\hline I & 5 & 6 & 6 & Nilai pH Gel \\
\hline II & 5 & 6 & 6 & menurut SNI \\
\hline III & 5 & 6 & 6 & yaitu 4,5-6,5. \\
\hline Rata-rata & 5 & 6 & 6 & \\
\hline
\end{tabular}




\section{Prosiding Seminar Nasional Kesehatan 2021 Lembaga Penelitian dan Pengabdian Masyarakat Universitas Muhammadiyah Pekajangan Pekalongan}

Tabel 4. Hasil Uji Daya Lekat

\begin{tabular}{|c|c|c|c|c|}
\hline \multirow{2}{*}{ Replikasi } & \multicolumn{3}{|c|}{ Hasil Pengamatan } & \multirow{2}{*}{ Pustaka } \\
\cline { 2 - 4 } & F1 & F2 & F3 & \\
\hline I & 1,83 & 3,98 & 8,04 & Voight (1984) \\
daya lekat gel \\
II & 1,80 & 3,95 & 8,01 & yang baik adalah \\
\hline III & 1,76 & 3,91 & 7,98 & lebih dari 1 detik \\
\hline
\end{tabular}

Tabel 5. Hasil Uji Daya Sebar

\begin{tabular}{|c|c|c|c|c|}
\hline \multirow{2}{*}{ Replikasi } & \multicolumn{3}{|c|}{ Hasil Pengamatan } & \multirow{2}{*}{ Pustaka } \\
\cline { 2 - 4 } & F1 & F2 & F3 & \\
\hline I & 5,0 & 5,7 & 6,5 & Daya sebar gel \\
yang baik 5-7 \\
II & 5,1 & 6,0 & 6,6 & 6,7 \\
cm (garg, et al., \\
III & 5,2 & 6,1 & 6,6 & 2002) \\
\hline Rata-rata & 5,1 & 5,93 & 6 \\
\hline
\end{tabular}

\section{Pembahasan}

Pada penelitian ini tumbuhan bandotan didapatkan dari desa Sidomulyo, kecamatan Lebakbarang, kabupaten Pekalongan yang diambil secara acak dengan kondisi yang masih bagus. Evaluasi sediaan gel dilakukan untuk mengetahui sifat fisik gel ekstrak etanol daun bandotan dengan kombinasi karbopol dan HPMC yang baik dari berbagai kadar basis Karbopol dan HPMC. Dengan demikian dapat diketahui kesesuaian hasil uji dengan standar uji dari kepustakaan. Pada penelitian ini ada 3 formula dengan perbedaan konsentrasi basis gel Karbopol dan HPMC yaitu 2\%: 4\%; 0,875\% : 5,5\% dan 0,5\%:6\%. Hasil uji sediaan gel dapat dilihat pada Tabel diatas.

a. Uji Organoleptis

Tujuan uji organoleptis yaitu untuk mengetahui bentuk, warna dan bau pada sediaan gel ekstrak etanol daun bandotan dengan kombinasi karbopol dan HPMC. Hasil yang diperoleh pada semua formula sediaan gel berbentuk kental dan ketiga formula tersebut berwarna hijau kehitaman. Warna hijau kehitaman dikarenakan konsentrasi ekstrak yang digunakan terlalu besar yaitu 7,5\%. Berdasarkan tabel hasil pengamatan uji organoleptis dari ketiga formula diatas tidak terdapat perbedaan yang signifikan.

b. $\mathrm{Uji} \mathrm{pH}$

Tujuan pengukuran $\mathrm{pH}$ yaitu untuk mengetahui gel bersifat asam, basa atau netral. Nilai pH berhubungan dengan stabilitas zat aktif, efektifitas pengawet dan keadaan kulit. Berdasarkan tabel hasil pengukuran $\mathrm{pH}$ menunjukkan bahwa nilai $\mathrm{pH}$ sediaan untuk semua formulasesuai untuk sediaan topikal karena nilai $\mathrm{pH}$ memenuhi standart yaitu 4,5-6,5. Jika dibandingkan dengan penelitian sebelumnya tidak berbeda signifikan, yaitu penelitian dari Taufiq dan faradillah ameilia menjelaskan bahwa nilai $\mathrm{pH}$ dari sediaan gel ekstrak etanol herba bandotan memenuhi syarat untuk sediaan topikal. 


\section{Prosiding Seminar Nasional Kesehatan $\mathbf{2 0 2 1}$ Lembaga Penelitian dan Pengabdian Masyarakat Universitas Muhammadiyah Pekajangan Pekalongan}

c. Uji Daya Lekat

Tujuan uji daya lekat yaitu untuk mengetahui daya lekat gel terhadap kulit. Pengujian daya lekat merupakan parameter inti dalam pengujian gel yaitu untuk mengevaluasi gel dengan kelengketan, sejauh mana gel dapat menempel pada kulit sehingga zat aktifnya dapat diabsorbsi secara merata. Dari ketiga formula diatas hasil uji daya lekat yang memiliki nilai rata-rata yang paling tinggi adalah formula III, yang berarti memiliki daya lekat yang paling baik dengan kadar basis Karbopol dan HPMC 0,5\% : 6\%. Hal tersebut dikarenakan pada formula I bentuk gel yang lebih kental sehingga zat aktif dan basis gel kurang diabsorbsi dan kurang melekat pada alat, karena semakin besar konsentrasi karbopol maka semakin kental sediaan gel dan menyebabkan semakin susah pelepasan zat aktif dari pembawa. Namun, semua formula diatas telah memenuhi persyaratan daya lekat yang baik.

d. Uji Daya Sebar

Tujuan uji daya sebar yaitu untuk mengetahui sifat fisik gel yang dapat menyebar pada kulit dan dengan cepat pula memberikan efek terapinya dan untuk mengetahui kelunakan dari sediaan gel untuk dioleskan pada kulit. Pada uji daya sebar yang memiliki nilai rata-rata yang paling baik dan sesuai standart adalah pada formula III dengan kadar basis kombinasi karbopol dan HPMC 0,5\% : 6\% dan yang terendah pada formula I dengan nilai rata-rata sebesar $5,1 \mathrm{~cm}$. Nilai standart daya sebar yang baik untuk gel adalah diameter $5-7 \mathrm{~cm}$. Hal tersebut dikarenakan bentuk dari formula Ilebih kental dengan kadar basis yang lebih besar dibandingkan formula II dan III sehingga pada saat dilakukan uji daya sebar diatas kaca arloji penyebaran gel kurang sempurna akibatnya dalam pengukuran luas permukaan memiliki hasil yang rendah. Namun, semua formula diatas telah memenuhi persyaratan daya sebar yang baik. Jika dibandingkan dengan penelitian sebelumnya sangat berbeda signifikan, yaitu penelitian dari Taufiq dan faradillah ameilia menjelaskan bahwa hasil daya sebar dari sediaan gel ekstrak etanol herba bandotan 4,0-5,1 cm. Sedangkan nilai standart daya sebar yang baik untuk gel menurut Garg et al, 2002 yaitu 5 sampai $7 \mathrm{~cm}$. Sehingga terdapat sediaan gel ekstrak etanol herba bandotan yang tidak memenuhi persyaratan gel yang baik pada penelitian dari Taufiq dan faradillah ameilia, 2018.

\section{Simpulan}

Berdasarkan data hasil penelitian dapat disimpulkan bahwa gelling agent kombinasi karbopol dan HPMC dapat mempengaruhi sifat fisik gel yaitu organoleptis, $\mathrm{pH}$, daya lekat dan daya sebar pada sediaan gel ekstrak etanol daun bandotan (Ageratum Conyzoides L).Gelling agentkombinasi karbopol dan HPMC yang dapat memberikan pengaruh paling baik terhadap sifat fisik sediaan gel ekstrak etanol daun bandotan (Ageratum Conyzoides L) yaitu formula III. Hal ini dilihat dari hasil pengujian. 


\section{Prosiding Seminar Nasional Kesehatan \\ Lembaga Penelitian dan Pengabdian Masyarakat

\section{Referensi}

[1] Armstrong, N.A., \& James, K.C., 1996, Pharmaceutical Experimental Design and Interpretation, Taylor \& Francis Publiser, London.

[2] Bahri, Muchammad. 2016. Optimasi Emulgator Pada Lotion Repelan Ekstrak NHeksana Batang Serai Wangi (Cymbopogon nardus L). StudiEksperimental Metode Simplex Lattice Design.

[3] Kuncahyo, I. (2011). Optimasi Campuran Carbopol 941 dan HPMC dalam Formulasi Sediaan Gel Ekstrak Daun Jambu Mete secara Simplex Lattice Design Optimation of Carbopol 941 And HPMC Combination in Gel Formulation of Cashew Leaves Extract by Simplex Lattice Design. Jurnal Farmasi Indonesia, $8(1)(1), 1-12$.

[4] Maija, F. 2015. Uji Daya Hambat ekstrak daun Harrisonia perforrata Merr terhadap pertumbuhan bakteri stapylococcus aureus.Skripsi.Fakultas Matematika dan Ilmu Pengetauan Alam. Universitas Tadulako. Palu

[5] Mengkido,Melsi., Lambui,Orryani dan Harso, Wahyu. (2019). Uji Daya Hambat Ekstrak Daun Bandotan (Ageratum conyzoides L.) Terhadap Pertumbuhan Bakteri Staphylococcus aureus. Biocelebes, 13(2), 121-130.

[6] Priono, et al. 2021. Formulasi Fast Desintegrating Tablet (FDT) Ekstrak Etanol daun Kersen (Muntingia calabura L.) Dengan Kombinasi Sodium Starch Glycolate dan Avicel PH 102.Skripsi Fakultas Farmasi Universitas Muhammadiyah Purwokerto

[7] Purgiyanti dan Inur Tivani. 2019. PEMBUATAN DAN UJI SIFAT FISIK GEL ANTINYERI KOMBINASI MINYAK ATSIRI BUNGA CENGKEH ( Syzygium aromaticum(L.) Merr.\&Perry ) DAN SEREH (Cymbopogon nardus L. Rendle). JURNAL ILMIAH MANUNTUNG, 5(1), 38-41, 2019

[8] Rowe, R.C., et Al. 2006. Handbook of Pharmaceutical Excipient, 5th Ed, The Pharmaceutical Press. London.

[9] Sayuti, K, Rina Yenrina. 2015. Antioksidan Alami dan Sintetik; Andalas Univesity Press: Padang,

[10] Siska Rezkywianti. 2016. Optimalisasi Formulasi Tepung Terigu, Tepung Pare dan Tepung Daun Black Murberry Dalam Karakteristik Mi Kering Menggunakan Aplikasi Design Expert Metode Mixture D-Optimal. Bandung. Universitas Pasundan

[11] Syarifah, et al. 2015. Formulasi Sediaan Masker Gel Peel-off Ekstrak Daun Pepaya (Carica Papaya L.) Sebagai Anti Jerawat dan Uji Aktivitasnya terhadap bakteri propionibakterium acnes. Prosiding Penelitian SPeSIA Unisba.

[12] Tambunan, Suryani dan Teuku Nanda. 2018. Formulasi Gel Minyak Atsiri Sereh dengan Basis HPMC dan Karbopol. Majalah Farmasetik. 14(2) : 87-95

[13] Taufiq dan Faradillah Ameilia. 2018. Formulasi dan Uji Mutu Fisik Sediaan Gel Ekstrak Etanol Herba Bandotan (Ageratum conyzoides L.). 


\section{Prosiding Seminar Nasional Kesehatan \\ Lembaga Penelitian dan Pengabdian Masyarakat Universitas Muhammadiyah Pekajangan Pekalongan}

[14] Tiaraswara, R. A., \& D-optimal, M. (2015). Optimalisasi Formulasi Hard Candy Ekstrak Daun Mulberry (morus sp) dengan Menggunakan Design Expert Metode D-Optimal. Program Studi Teknologi Pangan.

[15] Titis rahayu , Achmad fudholi, Annisa fitria. 2016. Optimasi formulasi gelek strak daun tembakau (Nicotianatabacum) dengan variasi kadar karbopol 940 dan tea menggunakan metode simplex lattice design (sld). Jurnal ilmiah Farmasi 12 (1)

[16] Utami et,al. 2020. Pengaruh Berbagai Metode Ekstraksi Pada Penentuan Kadar Flavonoid Ekstrak Etanol Daun Iler (Plectranthus scutellariodes). Fitofarmaka Jurnal IImiah Farmasi. 10(1): 76-83.

[17] Voight, R., 1994, Buku Pengantar Teknologi Farmasi, 572-574, diterjemahkan oleh Soedani, N., Edisi V, Yogyakarta, Universitas Gadjah Mada Press.

[18] Zhelsiana,et al .2016. Formulasi dan Evaluasi Sifat Fisik Masker Gel peel-off lempung bentonite. The 4 th UniversityResearch Coloquium. Surakarta. 